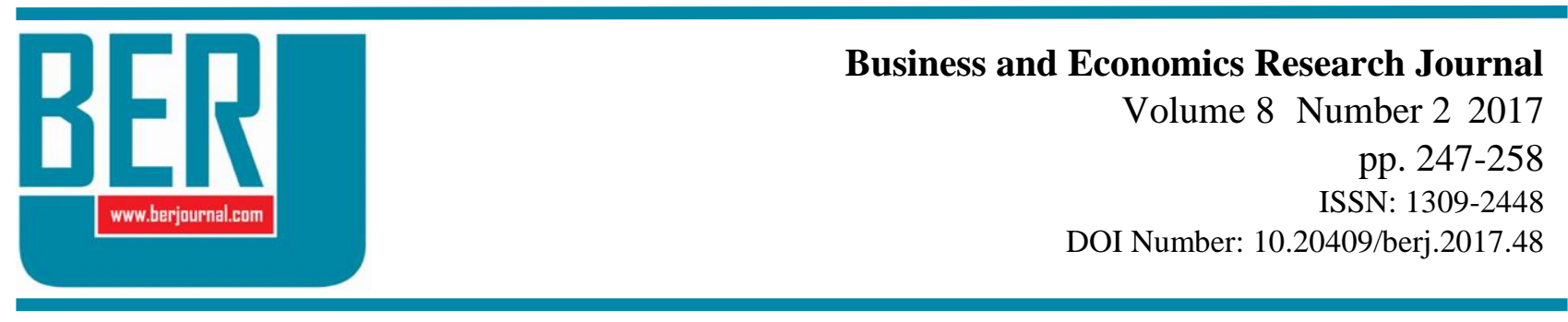

\title{
Finansal Başarısızlık ve Sermaye Yapısı Kararları: BIST 100 Endeksindeki Firmalar Üzerine Bir Uygulama
}

\author{
Tuncay Turan Turaboğlua
}

\author{
Aslı Yıkılmaz Erkol ${ }^{\mathrm{b}}$
}

\author{
Emre Esat Topaloğlu ${ }^{c}$
}

\begin{abstract}
Öz: Bu çalışmada, firmaların finansal başarııızıkları ile sermaye yapısı kararları arasındaki ilişkiyi ortaya çıkarmak amaçlanmıştr. Çalış̧mada, finansal başarısızık; Altman Z-Skor ve Springate S-Skor ile sermaye yapısı kararları ise; toplam borç oranı, borçların vade yapısı ve dışsal öz sermaye oranı ile temsil edilmiştir. Firma büyüklüğü ve duran varlık oranı kontrol değişkenleri olarak analize dâhil edilmiştir. Analiz sonucunda toplam borç oranı, kısa vadeli borç oranı ve dışsal öz sermaye oranı ile finansal başarııızık skoru arasında negatif yönde ve anlamlı bir ilişki belirlenmiştir. Dışsal öz sermaye oranı (yeni hisse senedi ihracı) ile finansal başarısızık skoru arasında belirlenen negatif yönlü ilişsi, Myers'in (1984) Finansal Hiyerarşi Teorisini (Pecking Order Theory) destekler niteliktedir. Yine; kontrol değişkenlerinden duran varlık oranı ve büyüklük değişkeni ile finansal başarııılık skoru arasında pozitif yönde ve anlamlı bir ilişki bulunmuştur. Bu çalışmada elde edilen sonuçlar, borçlanma oranının finansal başarısızığı arttırdığı yönünde bulgulara ulaşılan diğer çalışmaları ve denge teorisini (trade off theory) destekler niteliktedir.
\end{abstract}

Anahtar Sözcükler: Finansal Başarııızlık, Sermaye Yapısı Kararları, Altman Z-Skor, Springate S-Skor, Borsa İstanbul

JEL Sinıflandırması: G32, G35

\section{Financial Distress and Capital Structure Decision: An Aplication on BIST 100 Firms}

\begin{abstract}
This study aims to reveal the relationship between capital structure decisions and financial distress of the firms. In the study, the financial distressed are represented by the variables, Altman Z-Score and Springate S-Score while the capital structure decisions are represented by maturity structure of external debt and the equity capital ratio. The variables, namely firm size and the ratio of fixed assets are incorporated as control variables in the analysis. The results indicate a negative and significant relationship between financial distress and debt and equity ratios, namely total debt, short-term debt and equity ratios. The negative relationship between the external equity ratio (new equity issuance) and the financial failure score supports the Myers (1984) Pecking Order Theory. Moreover, a positive and statistically significant relationship is found between the control variables and financial success scores. The results of the study are consistent with the evidence of other studies and trade off theory that shows the debt ratio increases the probability of financial distress of the firms.
\end{abstract}

Keywords: Financial Distress, Capital Structure Decision, Altman Z-Score, Springate S-Score, Borsa İstanbul

JEL Classification: G32, G35

\footnotetext{
${ }^{a}$ Asst. Prof., PhD., Mersin University, Faculty of Economics and Administrative Sciences, Department of Business Administration, Mersin Turkiye, ttturaboglu@mersin.edu.tr

${ }^{\mathrm{b}}$ Res. Asst., Mersin University, Faculty of Economics and Administrative Sciences, Department of Business Administration, Mersin Turkiye, asli_yikilmaz@hotmail.com

'Res. Asst., Mersin University, Faculty of Economics and Administrative Sciences, Department of Business Administration, Mersin Turkiye, emresatopal@hotmail.com
} 


\section{Giriş}

Yükümlülüklerin yerine getirilememesi nedeniyle firmaların finansman kararlarını yeniden gözden geçirip değiştirmek zorunda kalmalarının yanı sıra, borçların zamanında ödenememesi, kredibilitenin azalması, konkordato ilanı, iflas ve iflasın ertelenmesi istemi gibi istenmeyen durumlarla karşılaşılması, finansal başarısızlık olarak adlandırılmaktadır. Finansal başarısızlık, firmaların faaliyet gösterdiği ekonomik çevreden kaynaklanabileceği gibi yönetim kurulu ve/veya üst düzey yönetimin aldığı kararların sonucu olarak da ortaya çıkabilmektedir. Yönetim zafiyeti, aşırı borçlanma, yetersiz çalışma sermayesi ve yetersiz nakit akımları firmaya özgü finansal başarısızlık nedenleri arasında bulunmakta olup sermaye yapısı kararları içerisinde yer alırlar. Firma büyüklüğü ve işletme yaşı gibi faktörler de sözü edilen finansal başarısızlık nedenlerini önemli ölçüde etkilemektedir.

Bilindiği üzere finansal kararlar karlılık risk ilişkisi çerçevesinde firma değerini etkiler. Her finansal karar para, zaman ve risk içerip; işletmenin bekası, üretimin devamı, varlıklara yatırım gücü, yükümlülüklerini yerine getirebilmesi, uygun kaynakların kullanılması ve uygun kar dağıtım politikalarının uygulanması için büyük önem taşır. Bir finansman yöneticisi, karar ve uygulamaları ile risk ve karlılık arasında denge sağlayarak işletme değerini arttırmalıdır. Buna göre sermaye yapısı kararları, firmalar açısından hem finansal başarısızlığa uğramanın ve hem de finansal başarısızlıktan kurtulmanın en önemli araçlarından birisidir. Eğer firma, sermaye yapısı kararları uyarınca aşırı düzeyde borçlanırsa, finansal yapısı bozulmakta, yükümlülüklerini yerine getirememekte ve belki de firmanın hukuki varlığının son bulmasıyla sonuçlanmaktadır. Diğer taraftan, finansal yapıyı sağlamlaştıracak, kaynak alternatiflerini artıracak ve daha ucuz çözümler bulunmasına yol açacak sermaye yapısı kararları, finansal başarısızlık olasılığının azaltımasını/ortadan kaldırılmasını sağlamaktadır. Finansal başarısızlık söz konusu olduğunda, toplam borçların azaltılması ve/veya borçların vade yapısının değiştirilmesi gibi yeniden yapılandırma uygulamaları gündeme gelmekte ve sözü edilen bu uygulamalar ile finansal başarısızlığın olası olumsuz etkileri azaltılmakta/ortadan kaldırılmaktadır.

Sermaye yapısı kararlarının, hem finansal başarısızlığın temel unsuru ve hem de finansal başarııızlığın önlenmesi veya olumsuz etkilerinin azaltılmasında kullanılabilen etkili bir araç olması, sermaye yapısı kararları ile finansal başarısızlık skoru arasındaki ilişkinin incelenmesini önemli bir konu haline getirmektedir. Bu açıdan çalışma, sadece finansal başarısızlığın tahmin yöntemleri ile belirlenmesini değil aynı zamanda ve sermaye yapısı kararları ile finansal başarısızlık arasındaki ilişkinin tespit edilmesini hedeflemektedir. Buna göre, öncelikle 2010-2015 yılları arasında sürekli olarak Borsa İstanbul (BIST) 100 Endeksi'nde yer alan firmaların, finansal başarı/başarısızlık durumları Altman Z-Skor ve Springate S-Skor Modelleri üzerinden belirlenecektir. Sonrasında ise firma performansını gösteren bu sonuçlar ile firma sermaye yapısı kararları arasında herhangi bir ilişkinin olup olmadığı, panel veri regresyon analizi ile ortaya çıkarılmaya çalışılacaktır. Bu itibarla, çalışmanın giriş bölümünü takiben konuya ilişkin literatüre yer verilecektir. Arkasından çalışmanın metodolojisi, finansal başarısızlığın ölçümlenmesi ve finansal başarısızık ile sermaye yapısı kararlarını arasındaki ilişkinin belirlenmesinde kullanılan yöntemlere dair açıklamalarda bulunularak analiz sonuçları değerlendirilecektir. Son olarak sonuç, değerlendirme ve öneri bölümü işlenecektir. Bu açıdan çalışma; diğer pek çok çalışmadan ayrılmakta ve Türkiye'de konuya ilişkin çalışma yapılmamış olmasından kaynaklanan eksikliği gideren özgün bir çalışma olarak, yazına katkıda bulunmaktadır.

\section{Literatür}

Finansal başarısızlık ve olası olumsuz etkilerinden firmayı ve paydaşlarını koruyabilmek ve gerekli önlemleri alabilmek için finansal başarısızlığın önceden belirlenmesi büyük önem arz etmektedir. Finansal başarısızlı̆ın önceden tespitine yönelik olarak genellikle çoklu diskriminant analizleri kullanılmakta olup bu yöntemler; Altman Z-Skor modeli, Altman, Haldeman, Narayanan Zeta analizi, Springate S-Skor modeli, Ohlson O-Skor modeli, Zmijewski J-Skor modeli, Cox Kısmi Tehlikeler modeli, Vassalou, Xing Yükümlülükleri Yerine Getirememe Olasılığı modeli ve Whited Wu Finansal Kısıtlar endeksi modeli olarak sıralanabilir ${ }^{1}$.

Finansal başarısızlığın belirlenmesi için farklı tahmin modellerinin kullanıldığı pek çok çalışma bulunmaktadır. Söz konusu çalışmalarda kullanılan tahmin modelleri ile elde edilen sonuçların, sonraki çalışmalarda veri olarak kullanıldığı bilinmekle birlikte, finansal başarısızlığa yönelik incelemelerin daha çok 
tahmin boyutunda kaldığı görülmektedir. Diğer bir deyişle, tahmin modellerinden elde edilen bulgular ile herhangi bir değişken arasındaki ilişkinin analiz edildiği çalışmalara nadiren rastlanmaktadır. Ulusal düzeyde herhangi bir çalışmanın olmadığı literatüre aşağıda yer verilmektedir.

Chancharat'ın (2008) Avustralya'da faaliyet gösteren 1.117 firmanın 1989-2005 dönemine ilişkin verilerini kullanarak gerçekleştirdiği çalışmada, finansal başarısızlık Cox Proportional Hazards Modeli ile ölçülmüştür. Kaldıraç oranının toplam borç oranı ile temsil edildiği çalışmadan elde edilen sonuçlara göre; finansal başarısızlığı yüksek firmalar büyük ölçekli, borç oranı yüksek ve hisse senedi getirisi düşük firmalardır. Firmaların borç oranındaki artış, finansal başarısızlık olasılığını arttırırken; hisse senedi getirisindeki artı̧, finansal başarısızıı olasılığını azaltmaktadır.

Chou, Li ve Yin (2010) tarafindan yapılan çalışmada; finansal başarısızlığın ve sermaye yapısının bağımsız yönetim kurulu üyelerinin performanslarına olan etkisi incelenmiştir. Finansal başarısızlığın belirlenmesinde, Altman Z-Skor ve Zmijewski J-Skor modelleri kullanılırken sermaye yapısı, finansal kaldıraç oranı ile temsil edilmiştir. Analiz kapsamına 2004-2006 yılları arasında S\&P500, S\&P MidCaps ve S\&P SmallCaps endekslerinde yer alan firmalar dahil edilmiştir. Analiz sonucunda, borçlanma düzeyini kontrol edemeyen şirketlerde, finansal başarısızlığın arttı̆ı tespit edilmiştir.

Lee, Koh ve Kang (2011), ABD'de gerçekleştirdikleri çalışmalarında, 1.648 firmanın 1990-2008 dönemindeki verilerini kullanarak finansal başarısılık skoru ile kaldıraç düzeyi ve sermaye yoğunluğu arasındaki ilişkiyi incelemişlerdir. Çalışmada, finansal başarısızlık modifiye edilmiş Altman Z-Skoru ile belirlenmeye çalışılırken kaldıraç oranı, toplam borç/öz sermaye oranı ile sermaye yoğunluğu ise duran varlıklar/toplam varlıklar oranı ile gösterilmiştir. Elde edilen sonuçlara göre kaldıraç oranı finansal başarısızlık skorunu negatif yönde etkilerken, sermaye yoğunluğu pozitif yönde etkilemektedir.

Chai ve Zhang (2011) 1975-2002 dönemi için ABD kapsamında gerçekleştirdikleri çalışmalarında, firmaların kaldıraç oranında meydana gelen değişimin ve aşırı borçlanmanın hisse senedi getirilerine etkisini araştırmışlardır. Çalışmada oluşturulan portföyler, finansal başarısızlık skorlarına göre gruplandırılarak firmaların borçlanma oranındaki değişimin, hisse senedi getirilerine etkisi görülmeye çalışılmıştır. Ohlson'un (1980) geliştirdiği O-Skor, Vassalou ve Xing'in (2004) ortaya koyduğu Yükümlülükleri Yerine Getirememe Olasılığı ve Whited ve Wu'nun (2006) önerdiği Finansal Kısıtlar Endeksi finansal başarısızlığın temsilcisi olarak kullanılmıştır. Elde edilen sonuçlara göre; aşırı borçlanma hisse senedi getirisini negatif yönde etkilemekte olup etkinin büyüklüğü finansal başarısızlık skoru yüksek olan firmalarda daha fazladır.

Ahmad (2013) Endonezya'da gerçekleştirdiği çalışmada; finansal başarısızlık olasılığı ile finansal oranlar ve yönetim yapısı arasındaki ilişkiyi incelemiştir. Finansal başarı skoru olarak Altman (1968), Altman vd. (1977), Ohlson (1980) ve Zmijewski (1984) tarafindan önerilen ölçüm yöntemlerinin kullanıldığı çalışmada, finansal oranların finansal başarısızlık üzerindeki etkisi lojistik regresyon yöntemi ile analiz edilmiştir. Elde edilen sonuçlara göre; finansal başarısızık olasılığı ile toplam borçlar / toplam öz sermaye oranı arasında pozitif yönde, aktif karlılığı ve öz sermaye karlııı̆ı arasında negatif yönde bir ilişki söz konusudur.

Kristanti, Rayahu ve Huda (2016) çalışmalarında; 2008-2013 döneminde hisse senetleri Endonezya Borsası'nda işlem gören aile firmalarının finansal oranları ve kurumsal yönetim uygulamaları ile finansal başarısızlık olasılıkları arasındaki ilişkiyi incelemişlerdir. Finansal başarısızlığın negatif hisse senedi getirisi ile temsil edildiği çalışmada, finansal başarısızlık ile finansal oranlar arasındaki ilişkinin analizinde lojistik regresyon yöntemi kullanılmıştır. Elde edilen sonuçlara göre firmaların kaldıraç oranı arttkça finansal başarısızlık olasılı̆ı da artmaktadır. Ayrıca; firma büyüklüğü, yönetim kurulu üyeliklerinin farklı cinsiyetler arasındaki dağıımı ve yönetim kurulu üyelerinin bağımsızlığı arttkça finansal başarısızlık olasılığı azalmaktadır.

Muigai'nin (2016) gerçekleştirdiği çalışmada; Kenya'da faaliyet gösteren firmaların finansal başarısızlık skoru ile sermaye yapısı kararları arasındaki ilişki 2004-2013 dönemi için incelenmiştir. Finansal başarısızlığın Altman Z-Skoru ile temsil edildiği çalışmanın sonuçlarına göre; finansal başarısızlık skoru ile finansal kaldıraç oranı arasında negatif yönde bir ilişki tespit edilirken, uzun vadeli borç ve içsel öz sermaye oranı ile pozitif yönde bir ilişkinin olduğu belirlenmiştir. 


\section{Veriler ve Yöntem}

Bu çalışmada, firmaların finansal başarısızlıkları ile sermaye yapısı kararları arasındaki ilişkinin ortaya çıkarılması amaçlanmıştır.

Tablo 1. Araştırmaya Dahil Edilen BIST 100 Firmaları (2010-2015)

\begin{tabular}{|c|l|c|l|}
\hline $\begin{array}{c}\text { BIST } \\
\text { KODU }\end{array}$ & \multicolumn{1}{|c|}{ ŞIRKETLER } & $\begin{array}{c}\text { BIST } \\
\text { KODU }\end{array}$ & \multicolumn{1}{c|}{ ŞiRKETLER } \\
\hline AEFES & ANADOLU EFES BIRACILIK & KARSN & KARSAN OTOMOTIV SAN TIC \\
\hline AFYON & AFYON CIMENTO & KARTN & KARTONSAN \\
\hline AKENR & AK ENERII ELEKTRIK URETIM & KOZAA & KOZA ANADOLU METAL MADENCILIK \\
\hline AKSA & AKSA AKRILIK & KRDMD & KARDEMIR D GRUBU \\
\hline ARCLK & ARCELIK & MGROS & MIGROS TICARET \\
\hline ASELS & ASELSAN & NETAS & NORTEL NETWORKS NETAS TELEKOM \\
\hline AYGAZ & AYGAZ & NTTUR & NET TURIZM TIC VE SAN \\
\hline BAGFS & BAGFAS & OTKAR & OTOKAR OTOMOTIV VE SAVUNMA SANAI \\
\hline BFREN & BOSH FREN SISTEMLERI & PETKM & PETKIM \\
\hline BIMAS & BIM BIRLESIK MAGAZALAR & PRKME & PARK ELEKTRIK URETIM MAD SAN \\
\hline BJKAS & BESIKTAS FUTBOL YAT SAN VE TIC & TCELL & TURKCELL ILETISIM HIZMETLERI \\
\hline DOAS & DOGUS OTOMOTIV & THYAO & TURK HAVA YOLLARI \\
\hline ENKAI & ENKA INSAAT VE BAYINDIRLIK & TOASO & TOFAS TURK OTOMOTIV FABRIKASI \\
\hline EREGL & EREGLI DEMIR CELIK & TRKCM & TRAKYA CAM \\
\hline FENER & FENERBAHCE FUTBOL & TTKOM & TURK TELEKOMUNIKASYON \\
\hline FROTO & FORD OTOMOTIV SANAYI & TUPRS & TUPRS TURKIYE PETROL \\
\hline GOLTS & GOLTAS GOLLER BOLGESI CIMENTO & ULKER & ULKER BISKUVI SANAYI \\
\hline GSRAY & GALATASARAY & ZOREN & ZORLU ENERI ELEK URET OTOPRD GR \\
\hline GUBRF & GUBRE FABRIKALARI & & \\
\hline
\end{tabular}

Kaynak: www.borsaistanbul.com

Tablo 2. Araştırmada Kullanılan Değişkenler

\begin{tabular}{|c|c|c|c|c|}
\hline \multicolumn{2}{|c|}{ Değişkenler } & Hesaplama Biçimi & \multirow{2}{*}{$\begin{array}{l}\frac{\text { Kaynak }}{\text { Chou, Li ve Yin (2010), }} \\
\text { Lee, Koh ve Kang (2011), } \\
\text { Muigai (2016), Chai ve } \\
\text { Zang (2011), }\end{array}$} & \multirow{2}{*}{$\begin{array}{l}\underline{\text { Simge }} \\
\text { TBO }\end{array}$} \\
\hline $\begin{array}{l}\text { Toplam } \\
\text { Borç Oranı }\end{array}$ & $\begin{array}{l}\text { Bağımsız } \\
\text { Değişken }\end{array}$ & $\begin{array}{l}\text { (Kısa Vadeli Borçlar Toplamı + Uzun Vadeli } \\
\text { Borçlar Toplamı) / (Kısa Vadeli Borçlar Toplamı } \\
\text { + Uzun Vadeli Borçlar Toplamı + Öz Sermayenin } \\
\text { Piyasa Değeri) }\end{array}$ & & \\
\hline $\begin{array}{l}\text { Borçların Vade } \\
\text { Yapısı }\end{array}$ & $\begin{array}{l}\text { Bağımsız } \\
\text { Değişken }\end{array}$ & $\begin{array}{l}\text { Kısa Vadeli Yabancı Kaynaklar Toplamı / Toplam } \\
\text { Varlıklar }\end{array}$ & Muigai (2016) & KVB \\
\hline $\begin{array}{l}\text { Dışsal } \\
\text { Öz Sermaye Oranı }\end{array}$ & $\begin{array}{l}\text { Bağımsız } \\
\text { Değişken }\end{array}$ & $\begin{array}{l}\text { (Toplam Öz Sermaye - Alıkonulan Karlar) / } \\
\text { Toplam Varlıklar }\end{array}$ & Muigai (2016) & DO \\
\hline $\begin{array}{l}\text { Altman } \\
\text { Z-Skoru }\end{array}$ & $\begin{array}{l}\text { Bağımlı } \\
\text { Değişken }\end{array}$ & $\begin{array}{l}\left(X_{1}\right) \text { Net Çalışma Sermayesi / Toplam Varlıklar } \\
\left(X_{2}\right) \text { Dağıtılmamış Karlar / Toplam Varlıklar } \\
\left(X_{3}\right) \text { Faiz ve Vergi Öncesi Kar / Toplam Varlıklar } \\
\left(X_{4}\right) \text { Piyasa Değeri / Toplam Borçlar } \\
\left(X_{5}\right) \text { Net Satışlar / Toplam Varlıklar } \\
Z=1,2 * X_{1}+1,4 * X_{2}+3,3 * X_{3}+0,6 * X_{4}+0,999 * X_{5}\end{array}$ & $\begin{array}{l}\text { Chou, Li ve Yin (2010), } \\
\text { Lee, Koh ve Kang (2011), } \\
\text { Ahmad (2013) }\end{array}$ & ZS \\
\hline $\begin{array}{l}\text { Springate } \\
\text { S-Skoru }\end{array}$ & $\begin{array}{l}\text { Bağımlı } \\
\text { Değişken }\end{array}$ & $\begin{array}{l}\left(X_{1}\right) \text { Çalışma Sermayesi / Toplam Varlıklar } \\
\left(X_{2}\right) \text { Faiz Vergi Öncesi Kar / Toplam Varlıklar } \\
\left(X_{3}\right) \text { Vergi Öncesi Kar / Kısa Vadeli Borçlar } \\
\left(X_{4}\right) \text { Satışlar / Toplam Varlıklar } \\
S=1,03 * X_{1}+3,07 * X_{2}+0,66 * X_{3}+0,4 * X_{4}\end{array}$ & & SS \\
\hline $\begin{array}{l}\text { Duran Varlık } \\
\text { Oranı }\end{array}$ & $\begin{array}{l}\text { Kontrol } \\
\text { Değişkeni }\end{array}$ & Toplam Duran Varlıklar / Toplam Varlıklar & Muigai (2016) & DV \\
\hline Firma Büyüklüğü & $\begin{array}{l}\text { Kontrol } \\
\text { Değişkeni }\end{array}$ & Log (Toplam Varlıklar) & $\begin{array}{l}\text { Richardson, Taylor ve } \\
\text { Lanis (2015) }\end{array}$ & TV \\
\hline
\end{tabular}


Bu amaç doğrultusunda; 2010-2015 yılları arasında Borsa İstanbul 100 Endeksi'nde (BIST 100) sürekli olarak yer alan 37 reel sektör firması çalışmaya dahil edilmiş olup finansal kuruluşlar, gayrimenkul yatırım ortaklıkları, holding ve yatırım ortaklıklarına yer verilmemiştir (Tablo 1). Kullanılacak değişkenler önceki çalışmalar dikkate alınarak belirlenmiş, söz konusu değişkenlere ait veriler, firmaların Borsa ìstanbul (www.borsaistanbul.com) ve Kamuyu Aydınlatma Platformu'nun (www.kap.org.tr) internet sitelerinde yayınlanan finansal raporlarından alınmıştı (Tablo 2).

Araştırmada yer alan firmaların finansal başarısızlık skorları ile sermaye yapısı kararları arasındaki ilişkinin panel veri kullanılarak incelendiği bu çalışmanın bağımlı değişkeni olan finansal başarısızlık skorları, Altman Z-Skor ve Springate S-Skor modelleri ile hesaplanmıştir.

Edward I. Altman tarafindan 1968'de geliştirilen Altman Z-Skor modeli, ilk olarak Amerika Birleşik Devletleri'nde (ABD) 1946-1965 döneminde finansal açıdan başarılı ve başarısız (iflas başvurusunda bulunan) 66 firma üzerinde uygulanmıştır. Firmaların Z-Skoru, farklı ağırlıklara sahip 5 faktörden oluşan pozitif yönlü bir fonksiyonu ifade etmektedir (Altman, 1968).

$\left(\mathrm{X}_{1}\right)$ Net Çalışma Sermayesi / Toplam Varlıklar

$\left(\mathrm{X}_{2}\right)$ Dağıtıımamış Karlar / Toplam Varlıklar

$\left(\mathrm{X}_{3}\right)$ Faiz ve Vergi Öncesi Kar / Toplam Varlıklar

$\left(\mathrm{X}_{4}\right)$ Piyasa Değeri / Toplam Borçlar

$\left(X_{5}\right)$ Net Satışlar / Toplam Varlıklar

$Z=1,2 * X_{1}+1,4 * X_{2}+3,3 * X_{3}+0,6 * X_{4}+0,999 * X_{5}$

Bu faktörler; likidite, karlıık, finansal kaynaklar, kapasite kullanım ve borç ödeme yeterliliğini gösteren 19 finansal orandan oluşmaktadır. Altman'ın (1968) modelinde; öncelikle yukarıda sıralanan finansal oranlar ve ağırlıklarını gösteren katsayılar hesaplanmış, sonrasında her bir finansal oran belirlenen bu katsayılarla çarpılıp toplanarak Z-Skoru elde edilmiştir. Z-Skora ilişkin faktörler ve fonksiyon yukarıdaki gibi ifade edilmektedir (I). Yukarıdaki eşitlik kurularak hesaplanan Z-Skor, $1,8<Z<2,7$ aralığı içerisinde değerlendirilmektedir. Buna göre; Z-Skor 2,7 ve üzerinde bir değer aldığında firmaların finansal olarak başarılı olduğu, finansal sıkıntı ve iflas maliyetleri ile karşı karşıya kalma olasılıklarının düşük olduğu kabul edilmektedir. Z-Skor'un 1,8' den düşük olması, firmaların finansal sıkıntı ve iflas maliyetleri ile karşılaşma olasılıklarının yüksek olduğu anlamını taşımaktadır. Öte yandan Z-Skor'un 1,8 ile 2,7 arasında bir değer alması ise firmaların finansal başarılarının normal seviyelerde olduğunun göstergesidir.

Altman (1968) tarafindan geliştirilen Z-Skor modeli; finansal başarısızlığın tahmin edilmesinin yanı sıra, yatırımcılara, kaynak sağlayan kişi ve kurumlara firmanın finansal durumuna ilişkin bilgi de sunmaktadır (Hauschild, 2013:6). Altman Z-Skor modelinin geliştirilmiş hali Springate S-Skor modelidir. Springate modeli, 1978 yılında Gordon L.V. Springate tarafindan ortaya atılmıştı. Altman Z-Skor modelinde popüler hale gelmiş 19 finansal oran arasından 4'ü seçilerek geliştirilen Springate S-Skor modeli, 40 şirket üzerinde test edilmiş ve \%92,5 doğruluk oranına ulaşmıştır. Springate S-Skor modelinin kurgusunda, 4 finansal oran ve ağırlıklarını belirleyen katsayılar yer almaktadır. Altman Z-Skor modelinde olduğu gibi bu modelde de her bir finansal oran, belirlenen bu ağırlıklar ile çarpılıp toplanarak S-Skor elde edilmektedir. S-Skor'a ilişkin faktörler ve fonksiyon aşağıdaki gibi ifade edilebilir:

$\left(X_{1}\right)$ Çalışma Sermayesi / Toplam Varlık

$\left(\mathrm{X}_{2}\right)$ Faiz Vergi Öncesi Kar / Toplam Varlık

$\left(\mathrm{X}_{3}\right)$ Vergi Öncesi Kar / Kısa Vadeli Borçlar

$\left(\mathrm{X}_{4}\right)$ Satışlar / Toplam Varlık

$S=1,03 * X_{1}+3,07 * X_{2}+0,66 * X_{3}+0,4 * X_{4}$

(II) 
Yukarıdaki eşitlik doğrultusunda hesaplanan S-Skor (II), 0,862' den düşük ise; firmaların finansal sıkınt ve iflas maliyetlerine katlanma olasılıklarının yüksek ve finansal açıdan başarısız oldukları kabul edilmektedir. Diğer taraftan S-Skor'unun bu değerin üzerinde bulunması; firmaların finansal sıkıntı ve iflas maliyetleri ile karşılaşma olasılıklarının düşük ve finansal açıdan başarılı olduklarının göstergesidir.

Bağımsız değişken konumunda bulunan sermaye yapısı kararları ise toplam borç oranı, borçların vade yapısı ve dışsal öz sermaye oranı ile ölçülmüştür. Ayrıca finansal başarısızlığı etkilediği düşünülen, firma büyüklüğü ve duran varlık oranı da kontrol değişkenleri olarak analize dahil edilmiştir. Modelin bağımlı değişkenini (I) ve (II) no'lu modellerin sonucu olarak elde edilen ve firmaların finansal başarısızlık durumunu gösteren Altman Z-Skor ve Springate S-Skorları oluşturmakta olup kurgulanan regresyon modelleri (III, IV) aşağıda gösterilmektedir.

Altman Z-Skoru Yöntemi Esas Alınarak Oluşturulan Regresyon Modeli

$$
Y_{i t}=\alpha_{0 i t}+\beta_{1 i t} T B O_{i t}+\beta_{2 i t} K V B_{i t}+\beta_{3 i t} D O_{i t}+\beta_{4 i t} T V_{i t}+\beta_{5 i t} D V_{i t}+\varepsilon_{i t}
$$

Springate S-Skoru Yöntemi Esas Alınarak Oluşturulan Regresyon Modeli

$$
Y_{i t}=\alpha_{0 i t}+\beta_{1 i t} T B O_{i t}+\beta_{2 i t} K V B_{i t}+\beta_{3 i t} D O_{i t}+\beta_{4 i t} T V_{i t}+\beta_{5 i t} D V_{i t}+\varepsilon_{i t}
$$

\section{Ampirik Bulgular ve Değerlendirilmesi}

BIST 100 Endeksinde yer alan firmaların finansal başarısızlıkları ile sermaye yapısı kararları arasındaki ilişkinin belirlenmesi amacıyla yapılan panel veri regresyon analizinden elde edilen bulgular aşağıda yer almaktadır. Ancak, araştırma bulgularını değerlendirmeden önce, analiz kapsamındaki değişkenlere ilişkin tanımlayıcı istatistiklere ve verilerin durağan olup olmadığını belirlemek için yapılan birim kök testi sonuçlarına değinilmesi yerinde olacaktır.

Ekonometrik modellerde bağımlı değişken ile bağımsız değişken/ler arasındaki ilişkiye dair anlamlı sonuçlar elde edilebilmesi için analizi gerçekleştirilecek serilerin durağan olması gerekmektedir (Gujarati, 2003). Bu çalışmada da, tüm serilerin durağanlık testleri, gözlem sayısının yetersiz olması nedeniyle PP-Fisher birim kök testleri ile araştrılmıştr. Birim kök testlerine ilişkin sonuçlar Tablo 3'te yer almakta olup görüleceği üzere sabitli ve sabitli/trendli modelde tüm seriler durağandır. Bu sonuç; finansal başarısızlık ile sermaye yapısı kararları arasındaki ilişkiyi test etmek için zaman serilerinin kullanılmasının yerinde bir yaklaşım olduğuna işaret etmektedir.

Tablo 3. Serilere Illişkin Birim Kök Testleri

\begin{tabular}{lcc}
\hline \multirow{2}{*}{ Değişkenler } & \multicolumn{2}{c}{ PP } \\
\cline { 2 - 3 } & Sabitli & Sabitli / Trendli \\
\hline ZS & $95,155^{* *}$ & $138,237^{* * *}$ \\
\hline SS & $118,744^{* * *}$ & $206,990^{* * *}$ \\
\hline KV & $131,988^{* * *}$ & $188,417^{* * *}$ \\
\hline TBO & $98,5386^{* *}$ & $205,240^{* * *}$ \\
\hline TV & $93,2801^{* *}$ & $187,561^{* * *}$ \\
\hline DV & $201,431^{* * *}$ & $201,811^{* * *}$ \\
\hline Not 1: ***\%1, **\%5, *\%10 anlamlılık düzeyini ifade etmektedir. \\
Not 2:Tabloda; Altman Z-Skor: ZS, Springate S-Skor: SS, Dışsal Öz Sermaye Oranı: DO, \\
Kısa Vadeli Borçlar: KVB, Toplam Borç, Oranı: TBO, Toplam Varlıklar: TV ve Duran \\
Varlıklar: DV ile gösterilmektedir.
\end{tabular}


Analizlerde kullanılan değişkenlere ilişkin tanımlayıcı istatistiklere Tablo 4'te yer verilmiştir.

Tablo 4. Değişkenlere Illişkin Tanımlayıcı İstatistikler

\begin{tabular}{lcccc}
\hline Değişkenler & Ortalama & Medyan & $\begin{array}{c}\text { Standart } \\
\text { Sapma }\end{array}$ & $\begin{array}{c}\text { Gözlem } \\
\text { Sayısı }\end{array}$ \\
\hline ZS & 4,4084 & 3,0689 & 4,7747 & 222 \\
\hline SS & 1,4881 & 1,4695 & 0,8931 & 222 \\
\hline DO & 0,3005 & 0,4080 & 10,518 & 222 \\
\hline KVB & 0,4171 & 0,2774 & 0,9048 & 222 \\
\hline TBO & 0,3965 & 0,4145 & 0,2073 & 222 \\
\hline TV & 21,467 & 21,694 & 15,917 & 222 \\
\hline DV & 0,3224 & 0,3011 & 0,1941 & 222 \\
\hline Not: Tabloda; Altman Z-Skor: ZS, Springate S-Skor: SS, Dışsal Öz Sermaye Oranı: DO, \\
$\begin{array}{l}\text { Kısa Vadeli Borçlar: KVB, Toplam Borç Oranı: TBO, Toplam Varlıklar: TV ve Duran } \\
\text { Varlıklar: DV ile gösterilmektedir. }\end{array}$ \\
\hline
\end{tabular}

Örneklem kapsamındaki firmaların ortalama Altman Z-Skoru 4,4; Springate S-Skoru ise 1,49'dur. Springate S-Skorunun 0,862'den, Altman Z-Skorunun 1,80'den küçük olmasının firmaların finansal açıdan başarısız olduğunu gösterdiği hatırlandığında, örnekleme dahil edilen firmaların finansal başarısızlıktan uzak olduğu sonucuna varılmaktadır.

\subsection{Altman Z-Skoru ve Sermaye Yapısı İlişkisi}

Finansal başarısızlık ile sermaye yapısı arasındaki ilişkinin Altman Z-Skoru kullanılarak incelendiği birinci modelde, modelin havuzlanmış en küçük kareler yöntemi ile tahmin edilip edilemeyeceği $F$ testi ve Breusch-Pagan Lagrange Çarpanı ile araştııımış olup elde edilen sonuçlar Tablo 5'te gösterilmektedir. Havuzlanmış en küçük kareler yönteminin uygunluğunu sınamak için kullanılan Breusch-Pagan Lagrange Çarpanı test sonuçlarına göre, modelin söz konusu yöntemle tahmin edilmeye uygun olmadığı ve modelde birim etkilerin var olduğu anlaşılmaktadır.

Tablo 5. F Testi ve LM Testi Sonuçları

\begin{tabular}{l|c|c}
\hline \multicolumn{1}{c|}{ Testler } & Değer & P Değeri \\
\hline F Testi & 8,2138 & 0,0000 \\
\hline Breusch-Pagan Lagrange Çarpanı Testi (LM) & 42,19 & 0,0000 \\
\hline
\end{tabular}

Havuzlanmış en küçük kareler yönteminin uygun olmadığı modelin sabit etkiler ya da rassal etkiler tahmincisi ile tahmin edilip edilemeyeceği ise Hausman testi ile sınanmıştır. Hausman testinin sonuçları Tablo $6^{\prime}$ da görülmekte olup Hausman test istatistiği olasılık değeri ( $p$ değeri) $0,05^{\prime}$ in altında olduğundan, modelin rassal etkiler tahmincisi ile tahmin edilmeye uygun olmadığı anlaşılmaktadır.

Tablo 6. Hausman Testi Sonuçları

\begin{tabular}{l|c|c}
\hline \multirow{2}{*}{ Hausman Testi } & Ki Kare İstatistiği & P Değeri \\
\cline { 2 - 3 } & 66,9633 & 0,0000 \\
\hline
\end{tabular}

Sabit etkiler tahmincisi kullanılarak tahmin edilen modelde, otokorelasyon ve değişen varyans problemlerinin olup olmadığına ilişkin ön testler yapılmıştır. Modelde değişen varyansın tespiti için Wald testi, otokorelasyonun tespiti için ise Durbin Watson testi ve Baltagi-Wu LBI testi kullanılmış olup test sonuçları Tablo 7'de gösterilmektedir. Wald test istatistiği olasılık değeri 0,05 'in altındadır ve modelde değişen varyans problemi olduğu anlaşılmaktadır. Literatürde kritik değerler verilmemekle birlikte, Baltagi-Wu LBI ve Durbin- 
Watson istatistik değeri 2' den küçükse, bu, otokorelasyonun önemli olduğu biçiminde yorumlanabilmektedir (Tatoğlu, 2012:214). Tablodan 7'den de görüleceği üzere Baltagi-Wu LBI ve Durbin Watson test istatistiği 2'den büyüktür.

Tablo 7. Değişen Varyans ve Otokorelasyon Testi Sonuçları

\begin{tabular}{l|c|c}
\hline \multicolumn{1}{c|}{ Testler } & Test Değeri & P Değeri \\
\hline Baltagi-Wu LBI & 2,1272 & \\
\hline Durbin-Watson & 2,1494 & \\
\hline Wald Testi & 53000 & 0,0000 \\
\hline
\end{tabular}

Modelde otokorelasyon, değişen varyans ve yatay kesit bağımlılığının olması durumunda birçok tahminci kullanılabilmektedir. Model tahmininde değişen varyans ve/veya otokorelasyon sorunlarından birinin bulunması halinde Tahmin Edilmiş Genelleştirilmiş En Küçük Kareler (EGLS) yöntemi veya Uygulanabilir Genelleştirilmiş En Küçük Kareler (FGSL) yönteminin kullanılması daha uygundur (Wooldridge, 2009:284; Baum, 2006: 159). Modelde değişen varyans problemi yatay kesit ağırlıklı GLS (Generalized Least Squares) yöntemi ve White'ın yatay kesit kovaryans katsayısı yöntemi (White's cross section coefficient covariance method) ile giderilmeye çalışımıştır. Ayrıca White'ın yatay kesit kovaryans katsayısı yöntemi kullanılarak yatay kesitler arası korelasyon sorununa da bir çözüm getirilmesi amaçlanmıştır (Korkmaz, Yıldız ve Gökbulut, 2010:102).

Altman Z-Skoru ile sermaye yapısı arasındaki ilişkinin incelendiği model, panel EGLS yöntemi ile analiz edilmiştir. Analiz sonuçları Tablo 8'de gösterilmektedir. Buna göre; modelin bir bütün olarak anlamlılığını ifade eden $\mathrm{F}$ istatistiği olasılık değeri \%99 güven aralığında anlamlıdır. Analizlere dahil edilen bağımsız değişkenler, Altman Z-Skorunda meydana gelen değişimlerin \%82'sini (R-kare) açıklamaktadır. Dışsal öz sermaye oranı, toplam borç oranı ve kısa vadeli yükümlülükler oranı ile Altman Z-Skoru arasında negatif yönde ve anlamlı bir ilişki tespit edilirken, büyüklük değişkeni ve duran varlık oranı ile Altman Z-Skoru arasında pozitif yönde ve anlamlı bir ilişki tespit edilmiştir. Firmaların sermaye yapısı içerisinde; borç oranı, kısa vadeli yükümlülüklerin toplam borç oranı içerisindeki payı ve dışsal öz sermaye oranı arttıkça finansal başarısızlık skoru azalmaktadır. Buna karşın, büyüklüğü ve duran varlık oranı artan işletmelerin finansal başarısızık skorlarının arttı̆ı belirlenmiştir.

Tablo 8. Panel EGLS Sonuçları

\begin{tabular}{|c|c|c|c|c|}
\hline \multicolumn{5}{|c|}{$\begin{array}{l}\text { Bağımlı Değişken: Altman Z-Skoru } \\
\text { Metod: Panel EGLS (Cross-section weights) } \\
\text { Örneklem Periyodu: 2010-2015 } \\
\text { Yatay Kesit Sayısı: } 37 \\
\text { Toplam Gözlem Sayısı: } 222 \\
\end{array}$} \\
\hline Değişkenler & $\begin{array}{c}\text { Korelasyon } \\
\text { Katsayısı }\end{array}$ & Standart Sapma & t-i̇statistiği & P Değeri \\
\hline $\mathbf{C}$ & -19.93004 & 4.394664 & -4.535053 & $0.0000 * * *$ \\
\hline DO & -1.033956 & 0.310320 & -3.331901 & $0.0010 * * *$ \\
\hline KVB & -0.770393 & 0.332416 & -2.317559 & $0.0216 * *$ \\
\hline TBO & -0.560445 & 0.205976 & -2.720925 & $0.0071 * * *$ \\
\hline DV & 1.089803 & 0.511557 & 2.130364 & $0.0345 * *$ \\
\hline TV & 1.157171 & 0.208853 & 5.540592 & $0.0000 * * *$ \\
\hline R-Kare & 0.828413 & \multicolumn{2}{|c|}{ Anlamlı Bağımlı Değişken } & 10.64729 \\
\hline Düzeltilmiş R-kare & 0.789329 & \multicolumn{2}{|c|}{ S.D. Bağımlı Değişken } & 7.767478 \\
\hline Regresyon S.E. & 2.373359 & \multicolumn{2}{|c|}{ Artıklar Kareler Toplamı } & 1013.910 \\
\hline F-istatistiği & 21.19581 & \multicolumn{2}{|c|}{ Durbin-Watson İstatistiği } & 1.901420 \\
\hline Prob (F-İstatistiği) & \multicolumn{3}{|c|}{$0.000000^{* * *}$} & \\
\hline
\end{tabular}




\subsection{Springate S-Skoru ve Sermaye Yapısı İlişkisi}

İkinci modelde finansal başarısızlık ile sermaye yapısı arasındaki ilişki Springate S-Skoru ile incelenmiştir. Modelin, havuzlanmış en küçük kareler yöntemi ile tahmin edilip edilemeyeceği $F$ testi ve Breusch-Pagan Lagrange Çarpanı ile araştırımıştır. Testlere ilişkin sonuçlar Tablo 9'da gösterilmektedir. Her iki testin sonuçlarına göre, modelin havuzlanmış en küçük kareler yöntemi ile tahmin edilmeye uygun olmadığı ve modelde birim etkilerin var olduğu anlaşıımaktadır.

Tablo 9. F Testi ve Breusch-Pagan Lagrange Çarpanı Testi

\begin{tabular}{l|c|c}
\hline \multicolumn{1}{c|}{ Testler } & Değer & P Değeri \\
\hline F Testi & 6,9980 & 0,0000 \\
\hline Breusch-Pagan Lagrange Çarpanı testi (LM) & 38,37 & 0,0000 \\
\hline
\end{tabular}

Modelin sabit etkiler ya da rassal etkiler tahmincisi ile tahmin edilip edilemeyeceği Hausman testi ile sınanmıştır. Hausman testi sonuçları Tablo $10^{\prime}$ da gösterilmekte olup olasılık değeri (p) $0,05^{\prime}$ in altında olduğundan, modelin rassal etkiler tahmincisi ile tahmin edilmesi uygun değildir.

Tablo 10. Hausman Test Sonuçları

\begin{tabular}{l|c|c}
\hline \multirow{2}{*}{ Hausman Testi } & Ki Kare İstatistiği & P Değeri \\
\cline { 2 - 3 } & 52,0373 & 0,0000 \\
\hline
\end{tabular}

Sabit etkiler tahmincisinin uygun olduğu anlaşılan model, sabit etkiler tahmincisi kullanılarak tahmin edilmiştir. Tahmin edilen modelde, değişen varyans Wald testi ile sınanırken, otokorelasyon ise Durbin Watson testi ve Baltagi-Wu LBI testi ile sınanmıştr. Sonuçlar Tablo 11'de gösterilmektedir. Wald test istatistiği olasılık değeri $0,05^{\prime}$ in altında olduğundan, modelde, değişen varyans problemi söz konusudur. Baltagi-Wu LBI ve Durbin Watson test istatistik değerleri 2'den küçük olduğu için modelde otokorelasyon sorunu bulunmaktadır.

Tablo 11. Değişen Varyans ve Otokorelasyon Testleri

\begin{tabular}{l|c|c}
\hline \multicolumn{1}{c|}{ Testler } & Test Değeri & P Değeri \\
\hline Baltagi-Wu LBI & 1,8393 & \\
\hline Durbin-Watson & 1,8263 & \\
\hline Wald Değişen Varyans & 15000 & 0,0000 \\
\hline
\end{tabular}

Modelde, oto korelasyon ve değişen varyans problemi, White'ın yatay kesit kovaryans katsayısı yöntemi ve yatay kesit ağırlıklı GLS (Generalized Least Squares) yöntemi ile giderilmeye çalışılmıştır. Modeldeki otokorelasyon sorunu White'ın yatay kesit kovaryans katsayısı yöntemi (White's cross section coefficient covariance method) ile standart hataların düzeltilmesi yoluyla giderilmeye çalışılmıştır.

Bu yöntem ile her bir yatay kesitteki farklı hata varyanslarının olduğu kadar aynı zamanda yatay kesitler arası korelasyon sorununa da bir çözüm getirilmesi amaçlanmıştır. Buna ek olarak, aynı boyuttaki değişken varyanslılığa izin vermek açısından yatay kesit ağırlıklı GLS (Generalized Least Squares) yöntemi de eşanlı olarak kullanılmıştır (Korkmaz vd., 2010:102). Springate S-Skoru ile sermaye yapısı arasındaki ilişkinin incelendiği modele ilişkin panel EGLS sonuçları Tablo 12' de gösterilmektedir.

Springate S-Skoru ile sermaye yapısı kararlarının incelendiği model, bir bütün olarak \%99 güven aralığında anlamlıdır. Elde edilen sonuçlara göre dışsal sermaye ve toplam borç oranı ile Springate S-Skoru arasında negatif yönde ve anlamlı bir ilişki bulunurken, büyüklük değişkeni ve duran varlık oranı ile Springate 
S-Skoru arasına pozitif yönde ve anlamlı bir ilişki tespit edilmiştir. Ayrıca kısa vadeli borç oranı ile Springate SSkoru arasında negatif yönde bir ilişki saptanmış ancak bu ilişki istatistiki olarak anlamlı bulunmamıştır.

Tablo 12. Panel EGLS Sonuçları

\begin{tabular}{lcccc}
\hline $\begin{array}{l}\text { Bağımlı Değişken: Springate S-Skoru } \\
\text { Metod: Panel EGLS (Cross-section weights) }\end{array}$ & & & \\
$\begin{array}{l}\text { Örneklem Periyodu: 2010-2015 } \\
\text { Yatay Kesit Sayısı: 37 }\end{array}$ & & & & \\
\begin{tabular}{l} 
Toplam Gözlem Sayısı: 222 \\
\multicolumn{1}{c}{ Değişkenler }
\end{tabular} & $\begin{array}{c}\text { Korelasyon } \\
\text { Katsayısı }\end{array}$ & Standart Sapma & t-ïstatistiği & P Değeri \\
\hline C & -5.378660 & 0.877848 & -8.131198 & $0.0000^{* * *}$ \\
\hline DO & -0.434263 & 0.128601 & -3.144994 & $0.0009^{* * *}$ \\
\hline KVB & -0.228104 & 0.146914 & 1.455132 & 0.1223 \\
\hline TV & 0.315424 & 0.039767 & 9.023147 & $0.0000^{* * *}$ \\
\hline DV & 1.157154 & 0.303264 & 4.471885 & $0.0002^{* * *}$ \\
\hline TBO & -0.131004 & 0.035138 & -2.673764 & $0.0003^{* * *}$ \\
\hline R-Kare & 0.957737 & Anlamlı Bağımlı Değişken & 4.076897 \\
Düzeltilmiş R-Kare & 0.948110 & S.D. Bağımlı Değişken & 5.464579 \\
Regresyon S.E. & 0.604279 & Artıklar Kareler Toplamı & 65.72746 \\
F-istatistiği & 99.48775 & Durbin-Watson İstatistiği & 1.910975 \\
Prob (F-İstatistiği) & $0.000000^{* * *}$ & & & \\
\hline
\end{tabular}

Not 1: ***\%1, **\%5, *\%10 anlamlılık düzeyini ifade etmektedir.

Not 2: Tabloda; Dışsal Öz Sermaye Oranı: DO, Kısa Vadeli Borçlar: KVB, Toplam Borç Oranı: TBO, Toplam Varlıklar: TV ve Duran Varlık Oranı: DV ile gösterilmektedir.

\section{Sonuç, Değerlendirme ve Öneriler}

Finansal başarısızlık skoru ile sermaye yapısı kararlarının incelendiği bu çalışmada, 2010-2015 döneminde BIST 100 endeksinde yer alan firmaların sermaye yapısı kararları ile finansal başarısızlık skorları arasındaki ilişki, panel EGLS yöntemi ile analiz edilmiştir. Elde edilen sonuçlara göre; Toplam Borç Oranı (TBO), Kısa Vadeli Borç Oranı (KVB) ve Dışsal Öz Sermaye Oranı (DO) ile finansal başarısızlık skoru arasında negatif yönde ve anlamlı bir ilişki tespit edilmiştir. Kontrol değişkenlerinden olan duran varlık oranı ve büyüklük değişkeni ile finansal başarısızlık skorları arasında pozitif yönde ve anlamlı bir ilişki tespit edilmiştir. Çalışmadan elde edilen sonuçlar; Lee, Koh ve Kang (2011) ve Muigai (2016) tarafindan yapılan çalışmaların sonuçlarına benzerken Chancharat (2008), Chou, Li ve Yin (2010) ve Ahmad (2013) tarafindan gerçekleştirilen çalışmaların sonuçlarıyla farklılıklar içermektedir.

Toplam borç oranı ile finansal başarısızlık skoru arasında tespit edilen negatif yönlü ilişki ise denge teorisinin firmaların finansal sıkınt maliyetleri nedeniyle belirli bir oranda borçlanması gerektiği öngörüsünü desteklemektedir. Firmaların toplam borç oranındaki artş, vergi tasarrufu yaratsa da, aşırı borçlanma nedeniyle finansal yükümlülükleri karşılayamama riski ile karşılaşan firmaların finansal başarısızlık skorunu negatif yönde etkilemektedir.

Analizler sonucunda; dışsal öz sermaye oranı (yeni hisse senedi ihracı) ile finansal başarısızlık skoru arasında belirlenen negatif yönlü ilişki, Myers'in (1984) Finansal Hiyerarşi Teorisini (Pecking Order Theory) destekler niteliktedir. Finansal hiyerarşi teorisine göre içsel öz sermaye (otofinansman) dış finansman intiyacının ortaya çıkmasına engel olmakta ve dış finansmandan kaynaklanan maliyetleri azaltmaktadır. İçsel öz sermaye oranının artması, dış finansman ihtiyacını azaltmakta ve finansal başarısızıı skorunu pozitif yönde etkilemektedir.

Finansal başarısızlık skorunu etkileyen faktörlerden biri de borçların vade yapısıdır. Toplam borçlar içerisinde kısa vadeli yükümlülüklerin artması, finansal riski arttırmakta ve finansal başarısızlık skorunu negatif yönde etkilemektedir. 
Bu çalışma, 2010 yılı öncesi verilerin incelenen döneme eklenmesi, farklı endeks ve/veya sektörlerin analize dahil edilmesi ya da alt sektörler bazında incelenmesi, Altman Z-Skor ve Springate S-Skor modellerinin dışındaki finansal başarısızlık tahmin modellerinin kullanılması ve farklı ekonometrik yöntemler uygulanması yoluyla gerçekleştirilecek çalışmalar ile daha da geliştirilebilir.

\section{Son Notlar}

1. Analizlerde Altman Z-Skor modeli ile Springate S-Skoru kullanıldığından, çalışmanın bundan sonraki bölümlerinde bu iki modele yönelik açıklamalarda bulunulacaktır.

\section{Kaynaklar}

Ahmad, G. N. (2013). Analysis of financial distress in Indonesian stock exchange. Review of Integrative Business and Economics Research, 2(2), 521-533.

Aiyabei, J. (2002). Financial distress: Theory, measurement and consequence. The Eastern Africa Journal of Humanities and Sciences, 1(1), 61-68.

Alireza, D., Saeid, J. K., \& Morteza, M. (2015). Working capital, firms performance and financial distress in firms listed in Tehran stock exchange (TSE). Indian Journal of Fundamental and Applied Life Sciences, 5(S1), 2086-2093.

Altman, E. I. (1968). Financial ratios, discriminant analysis and the prediction of corporation bankruptcy. The Journal of Finance, 23, 589-609.

Altman, E. I., Haldeman, R., \& Narayanan, P. (1977). Zeta analysis: A new model to identify bankruptcy risk of corporation, Journal of Banking \& Finance, (1), 29-54.

Baltagi, B. H. (2005). Econometric analysis of panel data. England: John Wiley\&Sons, Ltd.

Baum, C. F. (2006). An introduction to modern econometrics using stata. Stata Press: USA.

Borsa İstanbul (2016), Mali tablolar arşivi, www.borsaistanbul.com, Erişim Tarihi: 15.11.2016.

Breusch, T., \& Pagan, A. (1980). The lagrange multiplier test and its applications to model specification in econometrics. Review of Economic Studies, 47(1), 239-253.

Chai, J., \& Zhang, Z. (2011). Leverage change, debt overhang, and stock prices. Journal of Corporate Finance, (17), 391-402.

Chancharat, N. (2008). An empirical analysis of financially distressed Australian companies: The application of survival analysis. Dissertation of Doctor of Philosophy School of Accounting and Finance-Faculty of Commerce, University of Wollongong, http://ro.uow.edu.au/theses/401, 1-259.

Chou, H-I., Li, H., \& Yin, X. (2010). The effects of financial distress and capital structure on the work effort of outside directors, Journal of Empirical Finance, 17 (3), 300-312.

Gujarati, D.N. (2003). Basic Econometrics. New York: McGraw Hill Book Co.

Hauschild, D. (2013). Altman Z-score: Not just for bankruptcy: From z-score to "green zone" survivability. Amros Corporation, 4-19.

Hausman, J. A. (1978). Specification test in econometrics. Econometrica, 46(6), 1251-1271.

Hsin-I, C., Hui, L., \& Xiangkang, Y. (2010). The effects of financial distress and capital structure on the work effort of outside directors. Journal of Empirical Finance, 17, 300-312.

Kamuyu Aydınlatma Platformu (2016), Finansal tablolar, www.kap.org.tr, Erişim Tarihi: 15.11.2016.

Korkmaz T., Yıldız B., \& Gökbulut, R. İ. (2010). FVFM'nin IMKB ulusal 100 endeksindeki geçerliliğinin panel veri analizi ile test edilmesi. İstanbul Üniversitesi İşletme Fakültesi Dergisi, 39(1), 95-105.

Kristanti, F. T., Rayahu, S., Huda, A. N. (2016). Determinant of financial distress on Indonesian family firm. Procedia - Social and Behavioral Sciences, (219), $440-447$. 
Lee, S., Koh, Y., \& Kang, K. H. (2011). Moderating effect of capital intensity on the relationship between leverage and financial distress in the U.S. restaurant industry. International Journal of Hospitality Management. 30(2), 429-438.

Muigai, R. G. (2016). Effect of capital structure on financial distress of non-financial companies listed in Nairobi securities exchange. Dissertation of Doctor of Philosophy in Finance in the Jomo Kenyatta University of Agriculture and Technology.

Myers, S. C. (1984). The capital structure puzzle. The Journal of Finance, 39(3), 574-592.

Ohlson, J. A. (1980). Financial ratios and the probabilistic prediction of bankruptcy, Journal of Accounting Research, 18, 109-131.

Richardson, G., Taylor, G., \& Lanis, R. (2015). The impact of financial distress on corporate tax avoidance spanning the global financial crisis: Evidence from Australia. Economic Modelling, (44), 44-53.

Springate, G. L. V. (1978). Predicting the possibility of failure in a Canadian firm. Unpublished M.B.A. Research Project, Simon Eraser University.

Tan, T. K. (2012). Financial distress and firm performance: Evidence from the Asian financial crisis. Journal of Finance \& Accountancy, (11), 36.

Vassalou, M., \& Xing, Y. (2004). Default risk in equity returns, Journal of Finance, (59), 831-868.

Whited, T. M., \& Wu, G. (2006). Financial constraints risk, Review of Financial Studies, (19), 531-539.

Wooldridge, J. M. (2009). Introductory econometrics: A modern approach. South-Western Cengage Learning: USA

Yerdelen Tatoğlu, F. (2012). Panel veri ekonometrisi. İstanbul: Beta Yayınları.

Yusuf, M., Abdul Karim, Y. F., \& Yunus, F.M. (2014). Financial distress and performance relationship of banks in Malaysia. 5th International Conference on Business and Economic Research (5th Icber 2014) Proceeding.

Zmijewski, M. (1984). Methodological issues related to the estimation of financial distress prediction models, Journal of Accounting Research Supplement, (22), 59-86. 